\title{
Parental immunisation needs and attitudes \\ (PINA) survey in paediatric hospital clinics and \\ community maternal and child health centres in \\ Melbourne, Australia
}

Original Article

\author{
The Royal Children's Hospital \\ 50 Flemington Road, \\ Parkville 3052
}

\begin{abstract}
Authors:
Costa-Pinto $\mathbf{J}^{1}$

Willaby $\mathbf{H}^{2}$

Leask $\mathbf{J}^{2}$

Schuster $\mathbf{T}^{3,4}$

Ghazarian $\mathbf{A}^{3}$

O'Keefe $\mathbf{J}^{\mathbf{3}}$

Danchin $\mathbf{M}^{1,3,4}$

${ }^{1}$ Department of General Medicine, The Royal Children's Hospital, ${ }^{2}$ University of Sydney, Sydney Medical School, School of Public Health, Sydney, New South Wales, Australia ${ }^{3}$ Murdoch Childrens Research Institute, ${ }^{4}$ University of Melbourne, Melbourne, Victoria, Australia.
\end{abstract}

Corresponding Author:

This is the author manuscript accepted for publication and has undergone full peer review but has not been through the copyediting, typesetting, pagination and proofreading process, which may lead to differences between this version and the Version of Record. Please cite this article as doi: $10.1111 /$ jpc.13790

This article is protected by copyright. All rights reserved. 
Dr Jessica Costa-Pinto

The Royal Children's Hospital

50 Flemington Road,

Parkville 3052

jess.costapinto@gmail.com

+61401231467

This article is protected by copyright. All rights reserved. 


\title{
Parental immunisation needs and attitudes (PINA) survey in paediatric hospital clinics and community maternal and child health centres in Melbourne, Australia
}

\begin{abstract}
Aim

Despite Australia's high vaccination rates, an estimated 3.3\% of children are undervaccinated due to vaccine refusal and the proportion of parents with concerns is unclear. Amongst Australian parents, we aimed to determine the prevalence of vaccine concerns, resources and Health Care Providers (HCPs) accessed, and satisfaction with these resources in two different settings. We also aimed to identify relationships between level of vaccine concern, socioeconomic status (SES) and vaccine uptake.
\end{abstract}

\section{Methods}

Parents of children under five years attending general paediatric clinics in a tertiary paediatric hospital $(n=301 / 398,76 \%)$ and children under 19 months attending community maternal child health centres $(n=311 / 391,81 \%)$ completed the survey. Vaccination status was obtained from the Australian Childhood Immunisation Register (ACIR).

\section{Results}

Despite high support for vaccination (98\%, CI 97-99), 43\% of parents reported vaccine concerns (CI 40-47) including the number of vaccines given in the first two years $(25 \%$, CI 22 to 29$)$, vaccine ingredients (22\%, CI 19-25), allergies (18\%, CI 15-21), weakening of the immune system (17\%, CI 14-20), and autism (11\%, CI 8-13). HCPs were the most commonly accessed and trusted information source. $23 \%$ of parents reported insufficient knowledge to make good vaccination decisions (CI 20-26). There was little evidence of an association between parental vaccine acceptance or SES and vaccination status.

\section{Conclusions}

Despite high support for vaccines, nearly half of Australian parents have some concerns and a quarter lack vaccine decision-making confidence regarding childhood vaccines. Parents frequently access and report high trust in HCPs, who are best placed to address parental vaccine concerns through provision of clear information, using effective communication 
strategies. Further research in more highly-hesitant populations is required to determine the relationship between the level and nature of vaccination concerns and vaccine uptake.

\section{What is already known on this topic}

1. It is estimated that $3.3 \%$ of Australian children are under-vaccinated due to vaccine refusal.

2. An unclear proportion of Australian parents have vaccine-concerns that if not addressed, may lead them to delay or refuse vaccines.

\section{What this paper adds}

1. Nearly half or $43 \%$ of Australian parents in our population reported some concerns about vaccination, mainly surrounding vaccine safety.

2. Health care providers were the most commonly accessed resource for vaccine information, and were highly trusted.

3. These findings highlight the need for effective communication strategies in the consultation room to address the vaccine concerns of Australian parents.

This article is protected by copyright. All rights reserved. 


\section{Introduction}

Vaccination is a safe and highly effective measure to reduce vaccine preventable diseases (VPDs)[1] and is most effective when vaccine coverage is high [27], optimising both individual protection and herd immunity. Whilst current data reveals that between $91-93 \%$ of Australian children are fully immunised [2], vaccine objection leads to under-vaccination in an estimated $3.3 \%$ of children and approximately one-third of parents express vaccine concerns $[3,4]$. Vaccine coverage varies widely by region [2], with vaccine attitudes, beliefs and concerns, and select socio-economic factors putatively influencing timely vaccination[28]. In Australia, the degree to which access issues, logistical barriers and vaccine hesitancy contribute to under-vaccination is not currently well understood.

Previously reported specific vaccine concerns include vaccine-related adverse events[5,6]; the perceived potential for vaccines to overload the immune system[5]; the number of vaccines given[5]; pain associated with vaccination[6]; and a belief that vaccines may cause autism[7], allergies[8] or autoimmune diseases[8]. These concerns may be exacerbated by ready access to anti-vaccine information through the internet and social media[9].

It is clear that interactions between parents and Health Care Providers (HCPs) play a critical role in shaping attitudes towards vaccination[10]. While positive interactions encourage hesitant parents towards vaccination, poor interactions contribute to vaccine rejection[4]. Studies suggest that HCPs are the most frequently accessed source of vaccine information[11], and are highly trusted[5]. Unsurprisingly, parents of unvaccinated children are more likely to report low levels of trust in their paediatrician or $\operatorname{HCP}[11,12,13]$ and the government[13]. These parents are also more likely to trust media reports, alternative practitioners, and non-official sources of information that corroborate their vaccine-sceptical views[12,13].

Whilst there is evidence supporting interventions that improve access to vaccination[14], effective strategies for addressing vaccine acceptance are lacking[7,9]. It is now apparent that communication or dialogue-based interventions are needed in addition to the provision of knowledge[15]. There is concern that if HCPs do not adequately address parents' vaccine questions and concerns, the number of vaccine-hesitant parents or those delaying or refusing 
vaccines, may increase.

A Vaccine Communication Framework (VCF) has been proposed using five categories to understand parents' level of vaccine hesitancy: the 'unquestioning acceptor'; the 'cautious acceptor'; the 'hesitant'; the 'late or selective vaccinator'; and the 'refuser'[4]. It is unclear what proportion of parents fall into the latter three categories, which represent the upper end of the vaccine hesitancy spectrum, as there is currently no accurate tool to measure vaccine hesitancy and minimal Australian data available to address this knowledge gap.

In two different settings, we primarily aimed to estimate the prevalence of vaccine acceptance and specific vaccine-related concerns among Australian parents of pre-school children. Secondly, we investigated parents' use of, satisfaction with, and trust in their HCP and other vaccine-related resources. Finally, we explored the relationship between parental vaccine acceptance, SES and vaccination uptake.

\section{Methods}

\section{Design, setting, participants}

Surveys were conducted in two different settings. The hospital survey (PINA-H) targeted parents or legal guardians of children under five years old attending general paediatric outpatient clinics at the Royal Children's Hospital in Melbourne between September 2014 and June 2015. The community survey (PINA-C) targeted mothers of children under 19 months attending routine appointments with their community maternal and child health nurse $(\mathrm{MCHN})$, as the frequency of visits in older children sharply declines after 18 months, between December 2014 and May 2015. MCHN appointments are scheduled at 2, 4 and 8 weeks, and 4, 8, 12 and 18 months of age in Victoria. Recruitment for the community survey occurred in ten centres, across five local government areas in the Bayside Medicare Local region, in South-Eastern Melbourne. Parents with insufficient English skills were excluded.

Researchers recruited a convenience sample of at least 300 participants for each survey from parents waiting for their appointments. The survey was administered via computer tablets (iPad $4^{\text {th }}$ Generation Wi-Fi Cellular). Interest and eligibility of parents was ascertained, an information sheet provided, and consent obtained by checking a box on the iPad. Incomplete 
survey respondents were given the option of completing the survey by email, followed by reminder emails two and four weeks later, before being considered non-respondents.

\section{Main study measures}

Survey items were based on earlier studies $[16,17,18]$ and were developed through extensive consultation with the study team, including social scientists, vaccine experts and paediatricians. Specific concerns were quantified through the use of matrix style questions, with six-point Likert scale responses[19]. Parental consent was obtained to access immunisation records on the Australian Childhood Immunisation Register (ACIR) to assess adherence to the schedule recommended by the National Immunisation Program (NIP)[20]. Children were considered up-to-date with the NIP schedule if all recommended vaccines for their age had been given, with a one month grace period (i.e. if their most recent vaccination was due within the previous month and had not yet been given, but they had received all of their previous vaccines, they were still considered up-to-date). Socioeconomic status (SES) was determined using participant postcodes, based on Socioeconomic Index for Advantage (SEIFA)[21]. SEIFA scores were categorised into three groups of high, medium and low based on pre-determined values, with higher values representing greater relative socioeconomic advantage.

\section{Data management and Statistical analysis}

Survey data were collected and managed using Research Electronic Data Capture (REDCap), a secure, web-based application designed to support data capture and management for research studies [22]. Survey data was then transferred to Stata software (Stata/MP 14.2 for Windows)[23] for analysis. Health system utilisation and general demographic profiles were analysed using descriptive statistics and sample proportions were presented with 95\% confidence intervals (CI). The difference in proportions between the two surveys were calculated using proportion tests along with 95\% CI and p values. Chi-square test was performed to assess the association between VCF position statement and children with a medically-diagnosed condition requiring an altered vaccination schedule. To assess correlation between SEIFA score and parental concerns and access, Spearman rank correlation co-efficient was used. Somers' D was used to assess association between satisfaction with resources and SEIFA Score. Kruskal-Wallis test was used to assess the different in SEIFA score by VCF position. Logistic regression was used to predict the probability of vaccine uptake based on SEIFA Score. 


\section{Ethics}

Ethical approval was obtained from the Royal Children's Hospital HREC (numbers 34146B and 34233A) in addition to approval from the Department of Education and Early Childhood Development.

\section{Results}

\section{Participants/Demographics}

Of 482 parents approached for the hospital survey, 461 (96\%) were eligible to participate, with 21 excluded due to insufficient English-language skills. Of those eligible, 398 (86\%) were recruited, with 63 declining due to time constraints, 25 because they were 'not interested' and 12 for 'other' reasons, and 301 (76\%) of 398 completed the survey. Of 391 parents approached for the community survey, only one was ineligible due to insufficient English-language skills. Of these, 384 (98\%) were recruited with three declining due to time constraints, two because they were 'not interested', and one reported being 'opposed to vaccination', and $311(81 \%)$ completed the survey. Postcodes were provided by 612 participants and were linked to corresponding SEIFA Score.

Demographic characteristics including parental age and country of birth were similar between the two groups (Table 1). However, more community survey respondents reported that they had a university or postgraduate degree and lived in an area with a high SEIFA score compared to the hospital survey (Table 1). Mean age of child and relationship to child differed between the two groups as expected due to the different target populations.

\section{Support for vaccines, degree of vaccine hesitancy and confidence in decision-making}

Overall support for vaccination was high in both groups, with 98\% (CI 97 to 99) indicating that they 'strongly support' or 'generally support' childhood vaccination. However, 35\% (CI 32 to 39) of parents reported 'minor concerns', and a further 8\% (CI 6 to 10) reported significant concerns, leading to incomplete vaccination in almost 4\% (CI 2 to 5 ) of children (Table 2). While support for vaccination was similar between the two groups, more parents in the community group than the hospital group reported 'minor concerns' (Difference 7\%, 95\% CI 1 to 14 , p-value $=0.047)($ Table 2$)$. Nearly a quarter of parents $(23 \%$, CI 20 to 26) reported insufficient knowledge to make good vaccination decisions.

\section{Specific concerns}


The majority of parents agreed that vaccines were important (97\%, CI 95 to 98$)$, safe (95\%, CI 93 to 96), effective (96\%, CI 95 to 97), and necessary (98\%, CI 97 to 99) for their child, and that the NIP schedule was appropriate (93\%, CI 91 to 95) and designed by experts who cared (97\%, CI 96 to 98) (Table 3). However, 14\% (CI 12-17) were concerned that vaccines would do their child more harm than good. Access issues were reported by $10 \%$ (CI 8 to 12 ) of parents who agreed that it was difficult to get their child vaccinated.

The top concerns included children getting too many vaccines in the first two years of life (25\%, CI 22 to 29), vaccine ingredients causing serious harm (22\%, CI 19 to 25), and vaccination causing autism (11\%, CI 8 to 13$)$ and allergies (18\%, CI 15 to 21$)$. Concerns about the effect of vaccines on a child's immune system were also high with many parents agreeing that vaccines could weaken their child's immune system (17\%, CI 14 to 20) and preferring them to get natural immunity from VPDs (12\%, CI 9 to 14) (Table 3).

More participants in the hospital group agreed that their child's immune system was more sensitive than most ( $41 \%$ compared to $15 \%$, Difference $26 \%, 95 \%$ CI $20 \%$ to $32 \%$; p-value= $<0.001$ ) (Table 3). Participants in the hospital group were also more likely to agree that; because other children are vaccinated, it is not necessary to have their child vaccinated (Difference 6\%, 95\% CI 1\% to 10\%, p-value=0.008); the pain of vaccine needles is too great for their child to bear (Difference $10 \%, 95 \%$ CI 5\% to $15 \%$, p-value $=<0.001$ ); vaccines are given to children to prevent diseases that are not serious (Difference 9\%, 95\% CI 4\% to 14\%, $\mathrm{p}$-value $=<0.001)$; and vaccines are given to children to prevent diseases that are not common (Difference $8 \%, 95 \%$ CI $1 \%$ to $14 \%$, p-value $=0.017$ ).

\section{Resources accessed by parents}

In both groups, HCPs were considered the most useful resource of vaccine information, and were most commonly accessed (Tables 4 and 5). GPs were most commonly accessed in the hospital group (72\%), compared to nurses in the community group (72\%) (Table 4). The community group reported accessing nurses, paediatricians, the internet, the Victorian Department of Health website, family and friends who are pro-vaccination and antivaccination compared to the hospital group (Table 4). A high SEIFA score was associated with accessing nurses (Somers' D 0.22 , CI 0.13 to 0.32 ) and family and friends who are provaccination (Somers' D 0.19 , CI 0.09 to 0.29 ). 
Parental satisfaction with resources accessed was highest with paediatricians (96\%), the Victorian Department of Health Website (95\%), nurses (95\%) and general practitioners (91\%) (Table 5). Satisfaction was also high among the $6 \%$ of parents who accessed complementary or alternative medicine practitioners (86\%). Anti-vaccination groups, and friends and family who opposed vaccination attracted the lowest satisfaction levels $(47 \%$ and $50 \%$ respectively).

\section{Trust in healthcare provider and willingness to pay to see a paediatrician}

Parents reported high trust in HCPs, with most trust in paediatricians (98\%), followed by nurses (96\%), GPs (94\%), and complementary and alternative medicine practitioners (91\%). There was no difference found between the hospital and community groups in trust expressed in the different HCPs. More participants in the community group indicated that they would 'probably' or 'definitely' pay an out-of-pocket expense for a vaccine-related 45-minute consultation with a paediatrician $33 \%$ in the community group and $21 \%$ in the hospital groups, Difference $11.7 \%$, $95 \%$ CI $0.4 \%$ to $23.8 \%$, p-value $=0.045$ ).

\section{Additional vaccination information requested by parents}

Many parents indicated that they would like more information about the risks of vaccination (71\%), vaccine side effects (71\%), how vaccines work (70\%) and safety-testing of vaccines $(70 \%)$. Fewer parents wanted information on the vaccine schedule $(65 \%)$, the risks of delaying vaccines $(60 \%)$ and the risks of VPDs $(60 \%)$.

\section{Factors related to vaccine acceptance}

There was no evidence that the median SEIFA score varied by self-reported vaccine hesitancy based on VCF categories (Figure 1). However the Kruksal-Wallis test suggested that the distribution of SEIFA score varied by VCF position statement with VCF category 5 excluded due to the small numbers $(p$-value $=0.0457$ ). There was no evidence of an association between SEIFA score and specific vaccine concerns ( $\mathrm{r}$ ranges between -0.17 to 0.05 with $\mathrm{p}$ value $>.05$ ). Higher levels of parental vaccine concern were associated with the participants' child having a medically-diagnosed condition requiring an altered vaccination schedule (Chi-square $=31.25$ (4df), p-value , <.001).

\section{Australian Childhood Immunisation Register (ACIR) data}

In the hospital group, 217 (72\%) of 301 parents consented to ACIR access, but data was only obtained for 164 (54\%) of 301 children due to insufficient or incorrect details to enable 
accurate ACIR retrieval. Similarly, in the community group, 233 (75\%) of 311 parents consented to ACIR access but data was only obtained for $183(59 \%)$ of 311 . There were high levels of adherence to the NIP schedule at all time points and there was little evidence of an association in vaccination adherence identified between parents of different VCF categories (Table 6). Adherence for unquestioning acceptors was between 93-100\% and for cautious acceptors between $89-96 \%$, with the lowest level of adherence of $89 \%$ in the latter group being at 6 months. There were only 15 parents in the higher hesitancy categories ('hesitant', 'late or selective vaccinator' and 'refuser'), minimising the likelihood to be able to assess associations between the degree of vaccine hesitancy according to the VCF and specific vaccine concerns and vaccine uptake (Table 6). There was no evidence of an association between SEIFA score and vaccine uptake $(\mathrm{n}=324$, OR 1.00; $95 \%$ CI 0.99 to 1.01 ; p-value = $0.079)$.

\section{Discussion}

Our study provides current information about the level of vaccination acceptance and vaccine-related concerns of Australian parents. Despite high reported adherence to the NIP schedule, $43 \%$ of parents indicated some level of vaccine concern. Consistent with previous studies $[5,6,7,8,11,17,25]$, parental concerns most commonly centred around vaccine safety, with less concern about the severity and susceptibility of VPDs.

Despite compelling evidence to the contrary [24] $11 \%$ of parents continue to worry that vaccines can cause autism, underlying the ongoing need to address this concern amongst parents[7]. Furthermore, more parents in the hospital group reported that their child's immune system was more sensitive than most and that the pain of needles was too much to bear. Hospitalised children access the health system more and may require more frequent or special risk vaccines, and providers need to take time to enquire about and address their vaccine concerns. In addition, access issues were reported by $10 \%$ of parents, and while specific barriers to access were not explored in this study, these should be further investigated as strategies to improve access have been shown to increase vaccination rates[14].

HCPs were the most highly accessed and trusted vaccine resource by parents. Both the hospital and community groups accessed GPs most frequently but nurses were also highly accessed in the community for vaccine information. In Australia, GPs and immunisation nurses are the first line providers of paediatric care, unlike in the USA. Thus, optimising 
effective vaccine-related discussions with well-trained and well-resourced HCPs is essential to maintain vaccine confidence and to address vaccine hesitancy amongst Australian parents, in both primary and seconday care. Paediatricians also need to take on a greater role in having these discussions with parents to decrease the burden of care on GPs, with many espressing a desire to be up-skilled in vaccine knowledge and communication skills [30]. However, parents need to pay a gap fee to see a community paediatrician for a longer, vaccine-related consultation, compared to a GP. While some parents were willing to pay a \$125 gap fee this would not be financially feasible for all parents and thus both groups of providers need to be well-equipped to deal with parents' concerns (approximately 40\% indicated that they would not be willing to pay at all).

A quarter of parents lacked confidence in their vaccine decision-making, with additional knowledge on vaccine safety being prioritised over the risks of VPDs. This is not surprising given the declining rate of VPDs in most developed countries, with parents having more fear of vaccines than the diseases as they are less visable than in the past. We would suggest that providers discussions with parents should be tailored to their top concerns and supported with clear, simple resources [25]. Furthermore, it is imperitive that communication strategies are incorporated as part of the healthcare encounter [15].

This study provides insight into the vaccine concerns of Australian parents and provides valuable information for HCPs and policy-makers that can assist in the development of effective strategies to address vaccine hesitancy. While some recent studies have explored the vaccine concerns of Australian parents [17,29], ours is the largest survey of parents specific vaccine concerns, information sources accessed, satisfaction with information resources and trust in HCPs. It also compares this information between two populations.

Our study has some limitations. Exclusion of non-English speaking parents and inclusion of parents already engaged with HCPs in community and hospital settings, and thus potentially more likely to support vaccines and report high HCP trust, may limit generalisibilty. However, high participation rates at MCHN visits, reported to be up to $100 \%$ for nurse home visits after birth which decline to $73 \%$ participation by 18 month MHCN visit, [26] suggest that the community group would be fairly representative of the general population. Unfortunately, with only half of all parents and a small proportion of highly hesitant parents $(\mathrm{n}=15$ in the three more hesitant VCF categories) providing permission for ACIR access, we did not have the power to correlate stated intentions according to the VCF or specific vaccine 
concerns with vaccine uptake. This highlights the difficulty in accessing vaccine hesitant parents and their reluctance to participate in studies and provide information, which may be related to distrust of the medical profession or fear of judgement. Participation in the study was not contingent on consent to ACIR access in order to include the views of more highly hesitant parents. Future research is clearly needed in more highly vaccine hesitant populations to better understand how intentions and specific vaccine attitudes and concerns, as well as SES correlate with vaccine uptake. Such research in different communities and populations will require high community engagement and trust to maximise participation.

\section{Conclusion}

This study highlights that nearly half of Australian parents have some concerns about vaccination and a quarter lack vaccine decision-making confidence regarding childhood vaccines. HCPs are the most frequently accessed vaccine resource by parents, with the highest reported high levels of satisfaction and trust. HCPs are best placed to address parental vaccine concerns through provision of clear, easily-digetible information, using effective communication strategies. Further research in more highly-hesitant populations is required to determine the relationship between the level and nature of vaccination concerns and vaccine uptake. 


\section{References}

1. Andre FE, Booy R, Bock HL, et al. Vaccination greatly reduces disease, disability, death and inequity worldwide. Bulletin of the World Health Organization. 2008 Feb;86(2):140-6.

2. Australian Government Department of Health. ACIR - Current Data, February 2016. Available from:

http://www.immunise.health.gov.au/internet/immunise/publishing.nsf/Content/acircurr-data.htm [Accessed 12 December 2016]

3. Beard FH, Hull BP, Leask J, et al.. Trends and patterns in vaccination objection, Australia, 2002-2013. Med J Aust. 2016 Apr 18;204(7):275.

4. Leask J, Kinnersley P, Jackson C, et al.. Communicating with parents about vaccination: A framework for health professionals. BMC pediatrics. 2012 Sep 21;12(1):1.

5. Bakhache P, Rodrigo C, Davie S, et al. .Health care providers' and parents' attitudes toward administration of new infant vaccines - A multinational survey. European journal of pediatrics. 2013 Apr 1;172(4):485-92.

6. Mills E, Jadad AR, Ross C, Wilson K. Systematic review of qualitative studies exploring parental beliefs and attitudes toward childhood vaccination identifies common barriers to vaccination. Journal of clinical epidemiology. 2005 Nov 30;58(11):1081-8.

7. Larson, H., Schulz, W (2015). The State of Vaccine Confidence 2015. The Vaccine Confidence Project, London School of Hygiene \& Tropical Medicine. Available at: http://www.vaccineconfidence.org/The-State-of-Vaccine-Confidence-2015.pdf [Accessed 16 December 2016]

8. Offit PA, Hackett CJ. Addressing parents' concerns: Do vaccines cause allergic or autoimmune diseases?. Pediatrics. 2003 Mar 1;111(3):653-9.

9. Leask J, Willaby HW, Kaufman J. The big picture in addressing vaccine hesitancy. Human vaccines \& immunotherapeutics. 2014 Sep 2;10(9):2600-2.

10. Gust DA, Darling N, Kennedy A, Schwartz B. Parents with doubts about vaccines: Which vaccines and reasons why. Pediatrics. 2008 Oct 1;122(4):718-25.

11. Salmon DA, Moulton LH, Omer SB, et al.. Factors associated with refusal of childhood vaccines among parents of school-aged children: A case-control study.

This article is protected by copyright. All rights reserved. 
Archives of pediatrics \& adolescent medicine. 2005 May 1;159(5):470-6.

12. Larson HJ, Schulz WS, Tucker JD, et al.. Measuring vaccine confidence: Introducing a global vaccine confidence index. PLOS Currents Outbreaks. 2015 Feb 25.

13. Brown KF, Kroll JS, Hudson MJ, et al.. Factors underlying parental decisions about combination childhood vaccinations including MMR: A systematic review. Vaccine. 2010 Jun 11;28(26):4235-48.

14. Ward K, Chow MY, King C, Leask J. Strategies to improve vaccination uptake in Australia, a systematic review of types and effectiveness. Australian and New Zealand Journal of Public Health. 2012 Aug 1;36(4):369-77.

15. Jarrett, C., Wilson, R., O’Leary, M., Eckersberger, E. and Larson, H.J., 2015. Strategies for addressing vaccine hesitancy - A systematic review. Vaccine, 33(34), pp.4180-4190.

16. Leask J, Chow M, Willaby H, Pemberton S. Parental attitudes towards childhood vaccination in Australia. PHAA 14th National Immunisation Conference; 18 June 2014; Melbourne, Australia.

17. Chow MY, Danchin M, Willaby HW, Pemberton S, Leask J. Parental attitudes, beliefs, behaviours and concerns towards childhood vaccinations in Australia: A national online survey. Australian Family Physician. 2017 Mar;46(3):145.

18. Centre for Epidemiology and Evidence. 2009-2010 Summary Report from the New South Wales Child Health Survey. Sydney: NSW Ministry of Health; 2012.

19. Allen IE, Seaman CA. Likert scales and data analyses. Quality Progress. 2007 Jul $1 ; 40(7): 64$.

20. Victoria State Government. Immunisation Schedule Victoria 2016. Available at: https://www2.health.vic.gov.au/public-health/immunisation/immunisation-schedulevaccine-eligibility-criteria/immunisation-schedule-victoria [Accessed 16 December 2016]

21. Australian Bureau of Statistics. 2033.0.55.001 - Census of Population and Housing: Socio-Economic Indexes for Area (SEIFA), Australia, 2011. Available at: http://www.education.vic.gov.au/Documents/about/research/FINAL\%20The\%20State \%20of\%20Victoria's\%20Children_2012\%20v2.pdf [Accessed 12 December 2016]

22. Harris PA, Taylor R, Thielke R, et al.. A metadata-driven methodology and workflow process for providing translational research informatics support. J Biomed Inform. 2009;42(2):377-81.

23. StataCorp. 2013. Stata Statistical Software: Release 13. College Station, TX: 


\section{StataCorp LP.}

24. Taylor LE, Swerdfeger AL, Eslick GD. Vaccines are not associated with autism: An evidence-based meta-analysis of case-control and cohort studies. Vaccine. 2014 Jun 17;32(29):3623-9.

25. Danchin M, Nolan T. A positive approach to parents with concerns about vaccination for the family physician. Australian family physician. 2014;43(10):690-4.

26. State Government Victoria, Department of Education and Early Childhood Development. The state of Victoria's children 2012: Early childhood - A report on how Victoria's young children are faring. Available at:

http://www.education.vic.gov.au/Documents/about/research/FINAL \%20The\%20State \%20of\%20Victoria's\%20Children_2012\%20v2.pdf [Accessed 8 December 2016]

27. Plotkin SA OW, Offit PA, editors. Vaccines. $6^{\text {th }}$ edn. Philadelphia: Saunders Elsevier, 2013.

28. Leask J, Danchin M. Imposing penalties for vaccine rejection requires strong scrutiny. Journal of paediatrics and child health. 2017 May 1;53(5):439-44.

29. Parrella A, Gold M, Marshall H, Braunack-Mayer A, Baghurst P. Parental perspectives of vaccine safety and experience of adverse events following immunisation. Vaccine. 2013 Apr 12;31(16):2067-74.

30. Costa-Pinto J, Willaby HW, Leask J, Wood N, Marshall H, Danchin M. Vaccine discussions with parents: The experience of Australian paediatricians. Journal of Paediatrics and Child Health. 2017 May 31.

This article is protected by copyright. All rights reserved. 
This article is protected by copyright. All rights reserved. 
Table 1. Characteristics of participants who completed the survey

\begin{tabular}{|c|c|c|}
\hline \multirow{2}{*}{$\begin{array}{l}\text { Characteristics } \\
\text { n (\%) }\end{array}$} & \multirow{2}{*}{$\begin{array}{l}\text { PINA-H } \\
\mathrm{n}=301\end{array}$} & \multirow{2}{*}{$\begin{array}{l}\text { PINA-C } \\
n=311\end{array}$} \\
\hline & & \\
\hline Mean parental age & 34.9 (SD 6.04) & $34.8(\mathrm{SD} 4.62)$ \\
\hline Mean child age (years) & $2.38(\mathrm{SD} 1.73)$ & 0.57 (SD 0.98) \\
\hline \multicolumn{3}{|l|}{ Country of Birth } \\
\hline Australia & $207(68.8)$ & $201(64.6)$ \\
\hline Other & $94(31.2)$ & $110(35.4)$ \\
\hline \multicolumn{3}{|l|}{ Level of Education } \\
\hline$<$ Year 12 & $31(10.3)$ & $4(1.3)$ \\
\hline Year 12 & $52(17.3)$ & $31(10)$ \\
\hline TAFE/ Apprenticeship & $48(16)$ & $29(9.3)$ \\
\hline University degree & $170(56.5)$ & $247(79.4)$ \\
\hline \multicolumn{3}{|l|}{ Marital Status } \\
\hline Single/never married & $18(6.0)$ & $5(1.6)$ \\
\hline Married/defacto/partnered & $270(89.7)$ & $303(97.4)$ \\
\hline Separated/divorced & $13(4.3)$ & $3(1)$ \\
\hline \multicolumn{3}{|l|}{ Relationship to Child } \\
\hline Mother & $246(81.7)$ & $311(100)$ \\
\hline Father & $53(17.6)$ & - \\
\hline Other & $2(0.6)$ & - \\
\hline \multicolumn{3}{|l|}{ SEIFA (Socioeconomic Index for } \\
\hline \multicolumn{3}{|l|}{ Advantage) Disadvantage } \\
\hline High & $45(15)$ & $141(45.3)$ \\
\hline Medium & $63(20.9)$ & $134(43.1)$ \\
\hline Low & $193(64.1)$ & $36(11.6)$ \\
\hline Aboriginal / Torres Strait Islander & $11(3.7)$ & $5(1.6)$ \\
\hline
\end{tabular}

This article is protected by copyright. All rights reserved. 
Table 2. Parental position on vaccination according to the Vaccine Communication Framework (VCF)

\begin{tabular}{|c|c|c|c|c|c|}
\hline VCF Statement & $\begin{array}{l}\text { PINA-H, } \\
\text { N=375 } \\
\text { n(\%) }\end{array}$ & $\begin{array}{l}\text { PINA-C, } \\
\text { N=362 } \\
\text { n (\%) }\end{array}$ & $\begin{array}{l}\text { Total } \\
\mathrm{N}=737 \\
\mathrm{n}(\%, 95 \% \mathrm{CI})\end{array}$ & $\begin{array}{l}\text { Difference } \\
\%(95 \% \mathrm{CI})\end{array}$ & P-value \\
\hline $\begin{array}{l}\text { Give all vaccines, no } \\
\text { concerns (Unquestioning } \\
\text { acceptor) }\end{array}$ & $225(60)$ & $194(54)$ & $\begin{array}{l}419(57,53 \text { to } \\
60)\end{array}$ & $6(-1$ to 13$)$ & 0.10 \\
\hline $\begin{array}{l}\text { Give all vaccines, } \underline{\text { minor }} \\
\text { concerns (Cautious acceptor) }\end{array}$ & $118(32)$ & $142(39)$ & $\begin{array}{l}260(35,32 \text { to } \\
39)\end{array}$ & $7(1-14)$ & 0.047 \\
\hline $\begin{array}{l}\text { Give all vaccines, a lot of } \\
\text { concerns (Hesitant) }\end{array}$ & $22(6)$ & 11 & $33(4,3$ to 6$)$ & $3(0$ to 6$)$ & 0.052 \\
\hline $\begin{array}{l}\text { Delay or exclude vaccines } \\
\text { (Late or selective vaccinator) }\end{array}$ & 10 & 10 & $20(3,2$ to 4$)$ & 0 (-2 to 2$)$ & 1.00 \\
\hline No vaccines (Refuser) & $0 \quad(0)$ & $5 \quad(1)$ & $5(1,0$ to 2$)$ & $1(-2$ to 2$)$ & 0.052 \\
\hline
\end{tabular}

This article is protected by copyright. All rights reserved. 
Table 3. Percentage of parents in each group who indicated that they 'strongly agree', 'moderately agree' or 'slightly agree' with the following statements

\begin{tabular}{|c|c|c|c|c|c|c|}
\hline \multirow[t]{2}{*}{ Statement } & \multicolumn{2}{|c|}{ PINA-H } & \multicolumn{2}{|c|}{ PINA-C } & \multicolumn{2}{|c|}{ Total } \\
\hline & $\mathbf{N} †$ & $\begin{array}{l}\text { Agree } \\
\text { n (\%) }\end{array}$ & $\mathbf{N} \dagger$ & $\begin{array}{l}\text { Agree } \\
\text { n (\%) }\end{array}$ & $\mathbf{N} †$ & $\begin{array}{l}\text { Agree } \\
\text { n }(\%, 95 \% C I)\end{array}$ \\
\hline $\begin{array}{l}\text { Vaccines are important for my } \\
\text { child }\end{array}$ & 366 & $352(96)$ & 356 & $348(98)$ & 722 & $700(97,95$ to 98$)$ \\
\hline $\begin{array}{l}\text { I worry that vaccines will do my } \\
\text { child more harm than good }\end{array}$ & 365 & $48(13)$ & 356 & $54(15)$ & 721 & $102(14,12$ to 17$)$ \\
\hline $\begin{array}{l}\text { It is difficult to get my child } \\
\text { vaccinated }\end{array}$ & 364 & $45(12)$ & 356 & $27(8)$ & 720 & $72(10,8$ to 12$)$ \\
\hline $\begin{array}{l}\text { The current schedule of } \\
\text { recommended vaccines is } \\
\text { appropriate for my child }\end{array}$ & 363 & $336(93)$ & 354 & $330(93)$ & 717 & $666(93,91$ to 95$)$ \\
\hline Vaccines are safe for my child & 363 & $347(96)$ & 354 & $334(94)$ & 717 & $681(95,93$ to 96$)$ \\
\hline Vaccines are effective for my child & 363 & $348(96)$ & 353 & $341(97)$ & 716 & $689(96,95$ to 97$)$ \\
\hline $\begin{array}{l}\text { Vaccines are necessary to protect } \\
\text { my child }\end{array}$ & 363 & $355(98)$ & 352 & $345(98)$ & 715 & $700(98,97$ to 99$)$ \\
\hline $\begin{array}{l}\text { The current childhood vaccination } \\
\text { schedule is designed by experts } \\
\text { who care about children's health }\end{array}$ & 362 & $353(98)$ & 352 & $341(97)$ & 714 & $694(97,96$ to 98$)$ \\
\hline $\begin{array}{l}\text { It is important for my child to be } \\
\text { vaccinated in order to protect } \\
\text { others in the community }\end{array}$ & 361 & $352(98)$ & 351 & $341(97)$ & 712 & $693(97,96$ to 98$)$ \\
\hline $\begin{array}{l}\text { Because other children are } \\
\text { vaccinated, it isn't necessary to } \\
\text { have my child vaccinated }\end{array}$ & 360 & $45(13)$ & 352 & $23(7)$ & 712 & $68(10,8$ to 12$)$ \\
\hline $\begin{array}{l}\text { My child's immune system is more } \\
\text { sensitive than most }\end{array}$ & 360 & $148(41)$ & 352 & $54(15)$ & 712 & $202(28,25$ to 32$)$ \\
\hline $\begin{array}{l}\text { Children get too many vaccines } \\
\text { during the first two years of life }\end{array}$ & 351 & $98(28)$ & 345 & $79(23)$ & 696 & $177(25,22$ to 29$)$ \\
\hline $\begin{array}{l}\text { Children's immune systems could } \\
\text { be weakened by vaccines }\end{array}$ & 349 & $62(18)$ & 344 & $55(16)$ & 693 & $117(17,14$ to 20$)$ \\
\hline $\begin{array}{l}\text { Vaccines contain ingredients that } \\
\text { can cause serious harm }\end{array}$ & 348 & $81(23)$ & 344 & $70(20)$ & 692 & $151(22,19$ to 25$)$ \\
\hline $\begin{array}{l}\text { The pain of vaccine needles is too } \\
\text { great for my child to bear }\end{array}$ & 347 & $74(21)$ & 344 & $38(11)$ & 691 & $112(16,14$ to 19$)$ \\
\hline $\begin{array}{l}\text { Vaccines are given to children to } \\
\text { prevent diseases that are not } \\
\text { serious }\end{array}$ & 342 & $57(17)$ & 344 & $27(8)$ & 686 & $84(12,10$ to 15$)$ \\
\hline $\begin{array}{l}\text { Vaccines are given to children to } \\
\text { prevent diseases that are not } \\
\text { common }\end{array}$ & 343 & $104(30)$ & 344 & $75(22)$ & 687 & $179(26,23$ to 29$)$ \\
\hline $\begin{array}{l}\text { Children should get natural } \\
\text { immunity from diseases rather than } \\
\text { immunity from vaccines }\end{array}$ & 342 & $45(13)$ & 343 & $34(10)$ & 685 & $79(12,9$ to 14$)$ \\
\hline Vaccines can cause autism & 340 & $39(11)$ & 342 & $33(10)$ & 682 & $72(11,8$ to 13$)$ \\
\hline Vaccines can cause allergies & 340 & $62(18)$ & 342 & $58(17)$ & 682 & $120(18,15$ to 21$)$ \\
\hline $\begin{array}{l}\text { There are better ways to protect } \\
\text { children against disease than } \\
\text { vaccines }\end{array}$ & 339 & $26(8)$ & 342 & $18(5)$ & 681 & $44(6,5$ to 9$)$ \\
\hline $\begin{array}{l}\text { Serious side effects from vaccines } \\
\text { are too common for me to accept }\end{array}$ & 337 & $31(9)$ & 342 & $26(8)$ & 679 & $57(8,7$ to 11$)$ \\
\hline
\end{tabular}

† Total number of parents who responded to the question. 
Table 4. Resources accessed by parents to address vaccine concerns.

\begin{tabular}{|c|c|c|c|c|c|}
\hline Resource & $\begin{array}{l}\text { PINA-H } \\
\text { N=329 } \\
\text { n† (\%) }\end{array}$ & $\begin{array}{l}\text { PINA-C } \\
\text { N=333 } \\
\text { n† (\%) }\end{array}$ & $\begin{array}{l}\text { Total } \\
N=662\end{array}$ & $\begin{array}{c}\text { Difference \% } \\
\text { (95\% CI) }\end{array}$ & P-value \\
\hline GP & $236(72)$ & $225(68)$ & $461(70)$ & $4(-3$ to 11$)$ & 0.261 \\
\hline Nurse & $187(57)$ & $239(72)$ & $426(64)$ & $15(8$ to 22$)$ & $<0.001$ \\
\hline Paediatrician & $151(46)$ & $125(38)$ & $276(42)$ & $8(1$ to 15$)$ & 0.037 \\
\hline Internet & $77(23)$ & $116(35)$ & $193(29)$ & $12(5$ to 19$)$ & $<0.001$ \\
\hline Family and/or friends who are pro-vaccination & $54(16)$ & $112(34)$ & $166(25)$ & $18(12$ to 24$)$ & $<0.001$ \\
\hline Victorian Department of Health website & $66(20)$ & $95(29)$ & $161(24)$ & $9(2$ to 15$)$ & 0.007 \\
\hline Family and/or friends who are anti-vaccination & $13(4)$ & $32(10)$ & $45(7)$ & $6(2$ to 10$)$ & 0.003 \\
\hline Complementary or Alternative Medical Practitioners & $18(5)$ & $25(8)$ & $43(6)$ & $3(1$ to 7$)$ & 0.118 \\
\hline $\mathrm{TV}$, radio, magazines & $16(5)$ & $26(8)$ & $42(6)$ & $3(1$ to 7$)$ & 0.118 \\
\hline None & $18(5)$ & $16(5)$ & $34(5)$ & $0(-3$ to 3$)$ & 1.000 \\
\hline Groups opposed to vaccination & $7(2)$ & $9(3)$ & $16(2)$ & $1(-3$ to 1$)$ & 0.410 \\
\hline Other & $6(2)$ & $9(3)$ & $15(2)$ & $1(-3$ to 1$)$ & 0.410 \\
\hline
\end{tabular}

†Number of parents who accessed these resources in the previous year

This article is protected by copyright. All rights reserved. 
Table 5. Parental satisfaction ${ }^{\dagger}$ with vaccination resources accessed

\begin{tabular}{|c|c|c|c|c|c|c|c|c|}
\hline \multirow[t]{2}{*}{ Resource } & \multicolumn{2}{|c|}{ PINA-H } & \multicolumn{2}{|c|}{ PINA-C } & \multicolumn{2}{|c|}{ Total } & \multicolumn{2}{|l|}{ Compariosn } \\
\hline & $\mathbf{N}$ & $\mathbf{n}(\%)$ & $\mathbf{N}$ & $\mathbf{n}(\%)$ & $\mathbf{N}$ & $n(\%)$ & $\begin{array}{l}\text { Difference \% } \\
(95 \% \mathrm{CI})\end{array}$ & P-value \\
\hline Paediatrician & 149 & $143(96)$ & 124 & $118(95)$ & 273 & $261(96)$ & $1(-4$ to 6$)$ & 0.690 \\
\hline GP & 233 & $210(90)$ & 225 & $206(92)$ & 458 & $416(91)$ & $2(-3$ to 7$)$ & 0.455 \\
\hline Nurse & 185 & $169(91)$ & 239 & $233(97)$ & 424 & $402(95)$ & $6(1$ to 10$)$ & 0.008 \\
\hline CAM & 18 & $16(89)$ & 25 & $21(84)$ & 43 & $37(86)$ & $5(-15$ to 25$)$ & 0.640 \\
\hline Internet & 76 & $56(74)$ & 116 & $85(73)$ & 192 & $141(73)$ & $1(-11$ to 13$)$ & 0.878 \\
\hline $\begin{array}{l}\text { Victorian Dept Health } \\
\text { website }\end{array}$ & 65 & $62(95)$ & 94 & $89(95)$ & 159 & $151(95)$ & $0(-6$ to 6$)$ & 1.000 \\
\hline $\mathrm{TV}$, radio, magazines & 15 & $13(87)$ & 26 & $17(65)$ & 41 & $30(73)$ & $22(-3$ to 47$)$ & 0.126 \\
\hline Anti-vaccination groups & 6 & $1(17 \%)$ & 9 & $6(67)$ & 15 & $7(47)$ & $5(1$ to 9$)$ & 0.057 \\
\hline $\begin{array}{l}\text { Pro-vaccination } \\
\text { friends/family }\end{array}$ & 52 & $44(85)$ & 112 & $97(87)$ & 164 & $141(86)$ & $2(-9$ to 13$)$ & 0.728 \\
\hline $\begin{array}{l}\text { Anti-vaccination } \\
\text { friends/family }\end{array}$ & 12 & $8(67)$ & 32 & $14(44)$ & 44 & $22(50)$ & $23(-9$ to 55$)$ & 0.174 \\
\hline
\end{tabular}

†Table represents those who rated satisfaction $>/=6$ on scale from 0 to 10

Table 6. Adherence to vaccination schedule by VCF position statement and time point

This article is protected by copyright. All rights reserved. 


\begin{tabular}{|c|c|c|c|c|c|c|c|}
\hline \multicolumn{2}{|c|}{ Position Statement } & \multirow{2}{*}{$\begin{array}{l}\mathbf{2 ~ m} \\
197\end{array}$} & \multirow{2}{*}{$\begin{array}{l}4 \mathrm{~m} \\
172\end{array}$} & \multirow{2}{*}{$\begin{array}{l}6 \mathrm{~m} \\
150\end{array}$} & \multirow{2}{*}{\begin{tabular}{|l|}
$12 \mathrm{~m}$ \\
107
\end{tabular}} & \multirow{2}{*}{$\begin{array}{l}18 \mathrm{~m} \\
82\end{array}$} & \multirow{2}{*}{\begin{tabular}{|l|}
$4 y$ \\
23 \\
\end{tabular}} \\
\hline Unquestioning & $\mathrm{N}$ & & & & & & \\
\hline & Adherent & 193 & 170 & 139 & 104 & 82 & 23 \\
\hline & \% Adherent & 98 & 99 & 93 & 97 & 100 & 100 \\
\hline \multirow{3}{*}{$\begin{array}{l}\text { Cautious } \\
\text { acceptor }\end{array}$} & $\mathrm{N}$ & 120 & 96 & 75 & 47 & 34 & 10 \\
\hline & Adherent & 115 & 92 & 67 & 44 & 32 & 9 \\
\hline & \% Adherent & 96 & 96 & 89 & 94 & 94 & 90 \\
\hline \multirow[t]{3}{*}{ Hesitant } & $\mathrm{N}$ & 8 & 8 & 7 & 3 & 3 & 1 \\
\hline & Adherent & 8 & 8 & 7 & 3 & 3 & 1 \\
\hline & \% Adherent & 100 & 100 & 100 & 100 & 100 & 100 \\
\hline \multirow{3}{*}{$\begin{array}{l}\text { Late or selective } \\
\text { vaccinator }\end{array}$} & $\mathrm{N}$ & 5 & 5 & 2 & 1 & 1 & 0 \\
\hline & Adherent & 5 & 3 & 0 & 1 & 1 & 0 \\
\hline & \% Adherent & 100 & 60 & $\mathbf{0}$ & 100 & 100 & - \\
\hline \multirow[t]{3}{*}{ Refuser } & $\mathrm{N}$ & 0 & 0 & 0 & 0 & 0 & 0 \\
\hline & Adherent & 0 & 0 & 0 & 0 & 0 & 0 \\
\hline & \% Adherent & - & - & - & - & - & - \\
\hline \multirow[t]{3}{*}{ Total } & $\mathrm{N}$ & 330 & 281 & 234 & 158 & 120 & 34 \\
\hline & Adherent & 321 & 273 & 213 & 152 & 118 & 33 \\
\hline & \% Adherent & 97 & 97 & 91 & 96 & 98 & 97 \\
\hline
\end{tabular}

This article is protected by copyright. All rights reserved. 


\section{University Library}

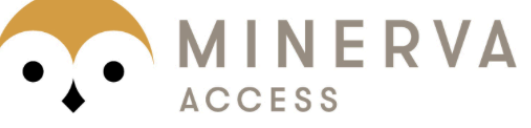

A gateway to Melbourne's research publications

Minerva Access is the Institutional Repository of The University of Melbourne

\section{Author/s:}

Costa-Pinto, JC;Willaby, HW;Leask, J;Hoq, M;Schuster, T;Ghazarian, A;O'Keefe, J;Danchin, $\mathrm{MH}$

Title:

Parental Immunisation Needs and Attitudes Survey in paediatric hospital clinics and community maternal and child health centres in Melbourne, Australia

Date:

2018-05-01

Citation:

Costa-Pinto, J. C., Willaby, H. W., Leask, J., Hoq, M., Schuster, T., Ghazarian, A., O'Keefe, J. \& Danchin, M. H. (2018). Parental Immunisation Needs and Attitudes Survey in paediatric hospital clinics and community maternal and child health centres in Melbourne, Australia. JOURNAL OF PAEDIATRICS AND CHILD HEALTH, 54 (5), pp.522-529. https:// doi.org/10.1111/jpc.13790.

Persistent Link:

http://hdl.handle.net/11343/293908 